\title{
Relações de controle nas aulas de Didática
}

\author{
Control relationships in the didactics classroom
}

\author{
Relaciones de control en las clases de didáctica
}

ANA CAROLINA COLACIOPPO RODRIGUES*

$\diamond$

\begin{abstract}
RESUMO
Este estudo dedica-se à análise de relações de controle estabelecidas nas aulas de Didática. Busca compreender mecanismos subjacentes às práticas desenvolvidas em seu ensino, no curso de Pedagogia, revelando aspectos do tipo de formação que vem sendo oferecido aos futuros docentes. Foi selecionada uma instituição privada para a coleta de informações, localizada na cidade de São Paulo. Estas foram coletadas por meio de observação e organizadas contando com cenas as quais foram analisadas com o uso de instrumentos pautados no conceito de enquadramento, de Bernstein. Seus resultados se referem aos indicadores de características das práticas para a formação da consciência profissional docente. Ressalta-se o controle constante do ritmo das atividades dos alunos pelo professor e a baixíssima condição avaliativa durante as aulas quanto aos trabalhos realizados pelos alunos e às explicações docentes.
\end{abstract}

Palavras-chave: Formação de professores. Didática. Relações de controle.

\begin{abstract}
This study is dedicated to the analysis of relationships of control established in classes of didatic. Seeks to understand mechanisms underlying of pedagogical practices developed in the teaching of didactic, in the faculty of Pedagogy, revealing aspects of the type of training that being provided to future teachers. Was selected a private institution to collect information, located in the city of São Paulo. The informations was collected through observation and organized using scenes. Such scenes were analyzed with the use of tools based on the concept of framing, of Bernstein. Its main results refer to indicators of the characteristics of pedagogical practices for the formation of professional awareness of teacher. It is emphasized the constant control of the rhythm of the activities of the students by the teacher and the very low evaluative condition during the class in relation to work carried out by students and teachers explanations.
\end{abstract}

Keywords: Teacher training. Didactic. Control relationships.

\section{RESUMEN}

Este estudio está dedicado al análisis de las relaciones de control establecido en las clases de didáctica. Busca comprender los mecanismos subyacentes de las prácticas desarrolladas en su enseñanza, en la facultad de Educación, mostrando aspectos del tipo de entrenamiento que se ha ofrecido a los futuros docentes. Se seleccionó una institución privada para la recolección de información, ubicada en ciudad de São Paulo. La información se recogió a través de la observación y se organizaron los datos con escenas. Tales escenas fueron analizadas utilizando instrumentos basado en el concepto de encuadre, de Bernstein. Sus conclusiones se refieren a indicadores de las características de prácticas para la formación de la conciencia profesional de los docentes. El estudio muestra el control constante de actividades de los alumnos por parte del profesor y la condición de evaluación muy baja en las clases en relación a las obras ejecutadas por los estudiantes y las explicaciones del professor.

Palabras clave: Formación del profesorado. Didáctica. Relaciones de control.

\footnotetext{
* Doutora em Educação: História, Política, Sociedade pela Pontifícia Universidade Católica de São Paulo. E-mail: <accolacioppo@hotmail.com>.
} 


\section{INTRODUÇÃO}

Este estudo analisa a disciplina Didática no curso de Pedagogia ${ }^{1}$.

No que tange a esse âmbito, as pesquisas frequentemente revelam informações que se referem à sua inocuidade nos cursos de licenciatura. As críticas evidenciam antigos problemas relacionados à prática que se remete à pedagogia tecnicista; à desvalorização da disciplina; à falta de articulação entre teoria e prática pedagógica; ao despreparo docente para trabalhar com os conhecimentos da área; à escassez de abordagem de conteúdos da sociologia e da psicologia nos planos de didática ou à "sociologização" do pensamento pedagógico; às falhas apresentadas nos documentos elaborados pelos professores e que balizam o ensino; e, enfim, à irrelevância da formação vivenciada na disciplina na visão dos alunos (MARIN, PENNA, RODRIGUES, 2012).

Essas circunstâncias ecoam nas instâncias de atuação profissional do licenciado. Estudos empíricos revelam graves problemas enfrentados pelos professores no que se refere ao aspecto didático de seu trabalho, tanto nos iniciantes quanto nos mais experientes (MARIN, 2008; GIOVANNI; MARIN, 2014).

Evidencia-se, portanto, sobretudo nessa disciplina, a necessidade de que os futuros docentes estudem e experienciem, no processo formativo, as atitudes, os modelos didáticos, as capacidades e os modos de organização que se pretende que sejam concretizados em suas práticas nas escolas.

Nesse contexto, a observação de diversificadas questões subjacentes às práticas auxilia na análise das relações estabelecidas no ensino dos conteúdos da disciplina, possibilitando o entendimento a respeito do modelo de formação estabelecido nas instituições. Há aspectos centrais na atuação didática dos professores e, portanto, também na atuação do professor de Didática.São estas as questões de ritmo de desenvolvimento do trabalho na sala de aula e as de critérios de avaliação, no que diz respeito ao grau de explicitação de conteúdos ao alunado, ao tipo de apreciação ou correção dos trabalhos dos alunos, ao grau de esclarecimento das dúvidas discentes e ao teor dos desafios ou questionamentos dirigidos aos alunos e aos tipos de respostas esperados e aceitos pelo professor. Esses critérios determinam a produção do texto legítimo em sala de aula (BERNSTEIN, 1996; 1998).

\footnotetext{
1 O artigo é oriundo de um trabalho maior que se dedicou ao relacionamento entre os mecanismos subjacentes às práticas pedagógicas no micro contexto da sala de aula ao macro contexto em relação às políticas de formação de professores, às expectativas que se tem do trabalho desse profissional na escola, evidenciando a organização das experiências vividas na disciplina Didática numa teia de relações que vem certificando professores para o trabalho com educação básica.
}

A avaliação tem sido foco de muitos estudos, sobretudo no ensino básico, mas, também, no ensino superior pela constância das medidas de avaliação externa. Entretanto, pouco se fala de análises sobre o processo no decorrer do próprio trabalho. Do mesmo modo, as questões de ritmo são sempre lembradas a propósito do início da escolarização, mas não no curso superior de formação de professores para atuar nessa faixa da escolaridade.

No que tange à área de avaliação, muito já se escreveu e se estudou sempre focalizando os seus aspectos formativos e técnicos de avaliar (GOMES, 2014; BARBIER, 1990; LUCKESI, 1995). Porém, parece ausente a análise de ações avaliativas focalizadas por outros ângulos como o das atitudes dos professores no decorrer do dia a dia das aulas com forte impacto formativo sobre os alunos. Em outra vertente, as questões de ritmo aparentam bastante dificuldade para seu estudo se escaparmos do cômputo dos minutos técnicos marcados. São assuntos envolvendo concepções que incidem fortemente no estudo, tanto do desempenho em sala de aula quanto para a obtenção de conhecimentos sobre tal situação.

Assim, neste estudo, a atenção está no controle interno nas aulas, no ritmo de desenvolvimento das aulas e em indicadores de critérios de avaliação no interior do curso de Pedagogia, como parte do foco nos modos pelos quais a disciplina Didática vem sendo ministrada. Este artigo relata relações de controle nos discursos dos docentes nesses aspectos, no interior de aulas de Didática, procurando responder à pergunta de como ocorrem essas relações e que formação implícita se propicia aos futuros professores no que tange a indicadores de ritmo de desenvolvimento das aulas e de critérios de avaliação. Para tanto, explicitam-se a seguir os fundamentos teóricos da pesquisa bem como relatam-se e analisam-se algumas cenas exemplificadoras.

\section{BASE TEÓRICA}

Para a realização do presente trabalho, optou-se pelo referencial de Bernstein (1996; 1998) em decorrência de o autor abordar o poder, a educação e a consciência. Partindo da noção de que a distribuição de poder e os princípios de controle de uma sociedade são traduzidos em princípios de comunicação que geram relações desiguais entre grupos, formam grupos dentro de sua classe e regulam as relações de oposição entre as classes sociais.

Os conceitos da teoria de Bernstein (1996; 1998) possibilitam a integração entre os níveis macro e micro de análise e a recuperação do macro a partir do micro, tratando de regras, práticas e agências que regulam a criação, distribuição, reprodução e mudança de consciência Isso mediante princípios de comunicação por 
meio dos quais uma distribuição de poder e categorias culturais dominantes são legitimadas e reproduzidas. Permitem compreender que formação é fornecida aos professores e como o ensino da Didática, por exemplo, ocorre no sentido de evidenciar os mecanismos que integram sua formação em relação às rotinas das escolas de educação básica e que são constituídos pelos modos de agir no sentido de ensinar desses professores nessa disciplina de formação inicial.

Há conceitos do autor com significativo potencial analítico e explicativo para o estudo das práticas pedagógicas. Ao discutirem os conceitos de classificação e enquadramento, Neves e Morais (2007) explicitam que a classificação diz respeito ao grau de manutenção de fronteiras entre categorias (professores, alunos, espaços, conteúdos de aprendizagem, escola, família, etc). Esta é forte quando há uma visível separação entre categorias, o que gera hierarquias em que cada categoria tem um estatuto e voz específicos e, assim, um determinado poder; a classificação é fraca quando ocorre o esbatimento das fronteiras entre categorias. $\mathrm{O}$ enquadramento diz respeito às relações sociais entre estas, isto é, à comunicação, sendo forte quando as que têm maior estatuto possuem o controle na relação, e fraco quando as categorias de menor estatuto também têm algum controle.

Ao utilizar os conceitos de classificação e enquadramento, Bernstein $(1996 ; 1998)$ baseava-se em dois tipos ideais de estrutura social. Um dos tipos pauta-se na regra "mantenham-se as coisas separadas". Quanto mais forte for essa regra, mais fortes serão a classificação e o enquadramento que controlam a transmissão. $\mathrm{O}$ controle é explícito e aparece como inerente a uma posição formal. O outro tipo de estrutura social baseia-se na regra "mantenham-se as coisas juntas". Nesse caso, o controle é implícito e aparece como inerente a uma pessoa e não a uma posição formal. A socialização dentro dessa regra encoraja comportamentos espontâneos, a manifestação das relações sociais e o seu questionamento, e os tipos sociais produzidos não são provavelmente fortes e bem marcados. A estrutura da socialização reflete relações de classificação e de enquadramento e são estas que modelam as estruturas mentais, estabelecendo procedimentos de codificação pautados em regras distintas.

Por trás da classificação e do enquadramento estão as relações de poder e os princípios fundamentais do controle social. O poder mantém a classificação, os isolamentos, as fronteiras entre as coisas. A modalidade de socialização, a interação pedagógica, é regulada pela intensidade do enquadramento.

"Juntos, a classificação e o enquadramento definem o que será comunicado e a forma de comunicação legítima em determinado agrupamento social" (GALIAN, 2009, p. 241). As relações discursivas referem-se a caracterís- ticas que compõem o código a ser adquirido no âmbito da sala de aula. O código é a lógica, a gramática, o princípio; e essa lógica possibilita que se instalem as relações de poder e controle como mensagens aos sujeitos, estabelecendo o lugar desses alunos na formação e, posteriormente, na prática profissional.

Com a análise das relações de poder e controle - e de suas variações nas práticas pedagógicas -, compreende-se o código na situação instrucional. Os conceitos de classificação e enquadramento possibilitam a análise do que é comunicado na sala de aula e como tal comunicação ocorre, definindo o código, portanto, neste estudo, a lógica da formação das consciências dos futuros professores. Como a distribuição do poder e do controle se traduzem em códigos pedagógicos e suas modalidades, as análises a partir do trabalho com os conceitos classificação e enquadramento possibilitam a compreensão do código subjacente às práticas desenvolvidas na disciplina.

Nesse contexto, teórico e empírico, este artigo se dedica especificamente à discussão de relações entre docente e alunos, contando com o conceito de enquadramento. $\mathrm{O}$ conceito de enquadramento possibilita a análise do controle exercido nas aulas de Didática. Quando este é forte, o professor controla os princípios da comunicação; quando é fraco, é como se o aluno vivesse uma situação em que parece ter algum controle sobre os princípios. $\mathrm{O}$ enquadramento fraco costuma mascarar o poder interno à categoria, cria a ilusão de que o espaço de comunicação que regula é negociável, mas isso não procede porque os transmissores são uma categoria especializada diferente e sempre há controles permeando a relação. Este delineia, ainda, a relação social. Quando o enquadramento muda em força, gera diferentes regras para operar a comunicação (BERNSTEIN, 1996; 1998). Assim, é possível, segundo essa teoria, identificar se os controles, nas aulas, estão com os alunos ou com o professor e em que graus são exercidos.

Segundo Neves e Morais (2007), são relevantes no nível da dimensão interacional e dentro da relação professor-aluno, por exemplo, as relações que se referem à seleção dos conhecimentos e competências, à sequência da aprendizagem, ao ritmo, e aos critérios de avaliação. Os princípios subjacentes a essas relações designam-se como regras discursivas, por se referirem aos princípios que regulam a transmissão-aquisição do discurso instrucional específico (DIE) - por exemplo, biologia, história, didática. As regras discursivas dizem respeito ao controle que os professores e alunos podem ter no processo de transmissão-aquisição; e o conceito de enquadramento permite estabelecer, para cada uma das regras, a natureza do controle. Por exemplo, este será forte, quanto às regras discursivas que regulam o DIE, se o professor tiver o controle sobre o tempo destinado à aprendizagem (ritmo) 
e se deixar claro aos alunos o texto a ser produzido como resultado da aprendizagem (critérios de avaliação); e será mais fraco quando o aluno tiver também algum controle no ritmo e nos critérios de avaliação.

Para se compreender o lugar dos alunos na formação e na prática profissional, contando com o conceito de enquadramento, pode-se pensar nos seguintes indicadores: o ritmo diz respeito ao tempo dedicado aos conteúdos abordados; os critérios de avaliação, determinam a produção do texto legítimo e referem-se ao grau de explicitação dos conteúdos trabalhados, aos questionamentos discentes, à apreciação dos trabalhos dos alunos e aos desafios aos alunos. Essas relações discursivas expressam relações de controle que ocorrem em sala de aula e podem apontar para um controle mais centrado no transmissor ou mais centrado no aluno (GALIAN, 2009). Assim, neste estudo, questiona-se: como ocorrem essas relações no ensino da Didática?

\section{A PESQUISA}

Este trabalho apresenta e discute mecanismos subjacentes às práticas de sala de aula no ensino da Didática em curso de Pedagogia ministrado por instituição representativa numericamente no que tange à alta quantidade de profissionais egressos anualmente. Busca compreender aspectos que revelem indícios do tipo de formação que vem sendo oferecida aos docentes dos anos iniciais da escolarização. Para isso, o campo empírico foi selecionado em decorrência de formar mais de mil egressos anualmente, no curso escolhido, na modalidade presencial, no âmbito da cidade de São Paulo. É uma das maiores instituições privadas do país.

O procedimento de observação de aulas foi central à análise das relações estabelecidas em sala de aula. A observação foi do tipo não participante. $\mathrm{E}$ a turma aqui focalizada foi observada durante um semestre - o terceiro de um curso de seis semestres -, em que os alunos cursaram a disciplina Didática I. Neste, a disciplina ocorre em dois semestres: a Didática I e a Didática II. O componente curricular foi ministrado uma vez por noite, a cada semana. A carga horária era de quatro horas por semana, sendo que na turma observada as aulas ocorreram às segundasfeiras, mas em nenhum dia preenchendo, de fato, o tempo previsto. A carga horária semestral da disciplina constava como 80 horas. O horárioprevisto era das $19 \mathrm{~h}$ às $23 \mathrm{~h}$, respectivamente, porém, geralmente, as aulas ocorriaam das $19 \mathrm{~h} 30$ às $22 \mathrm{~h}$ ou $22 \mathrm{~h} 30$. No total, foram observadas 39 horas de aula, distribuídas em 13 noites, na quais ocorreram as aulas da disciplina Didática I.

No período atual, que é posterior à defesa da tese de que este artigo é oriundo, estão previstos encontros com a professora observada a fim de evidenciar e discutir os resultados gerados pelo trabalho desenvolvido a partir das informações coletadas no contexto instrucional do campo empírico escolhido.

Estas foram organizadas em cenas analisadas contando com instrumentos compostos por escalas elaboradas pautadas no conceito de enquadramento. Nessas escalas, o grau de enquadramento varia em sua intensidade (E++, E+, E-, E--), conforme se verifica nos instrumentos apresentados no anexo. Quanto maior o enquadramento $(\mathrm{E}++)$, mais forte o controle por parte do professor e quanto mais fraco (E--), menos forte é o referido controle. Para cada cena foram utilizados quadros com escalas para a análise de excerto, sintetizando o desenvolvimento de práticas ocorridas. Neste artigo foram selecionadas quatro cenas representativas das análises e sínteses produzidas oriundas da tese, que é mais ampla do que aqui apresentado.

\section{O COMO DA PRÁTICA NA SALA DE AULA}

\section{Cena A}

Após o intervalo da aula, às $21 \mathrm{~h} 40$, a professora entrou em sala de aula e os alunos aguardavam calmamente o início. Avisou que passaria nos grupos para dizer qual o trecho de cada um do texto Competência e qualidade na docência, de Terezinha Azeredo Rios (2002).

Comunicou que eles deveriam ler e elencar as ideias principais.

Profa. Vocês têm que ler, mesmo que seja no barulho, cada um vai pensar numa apresentação diferente, quem leu menos na educação básica é que tem que ler mais agora.

Avisou que sortearia quem apresentaria de que jeito.

O texto foi dividido em partes, e cada grupo leu uma página.

No grupo observado, ocorreu a leitura coletiva sobre a retórica da qualidade. $\mathrm{O}$ grupo contava com seis pessoas e apenas dois textos. Uma aluna fez a leitura e as outras escutaram.

Os alunos tiveram dúvidas e não buscaram respostas.

O grupo observado ficou incumbido de preparar um jogral a partir da leitura da página selecionada. Outros grupos: acróstico, música, dramatização, receita, poesia, poema, cruzadinha, jogo.

Grupo do jogral - ficou escolhendo frases do texto para repetir.

Chamada: $22 \mathrm{~h}$.

A professora avisou que a atividade valeria um ponto.

E a turma ficou organizada em oito grupos, sendo que às $22 \mathrm{~h} 20$ a maioria já tinha ido embora, encerrando-se a aula.

Excerto - A professora pediu que os alunos se organizassem em grupos e dividiu o texto da Terezinha Rios em tópicos para que cada grupo ficasse responsável pela apresentação de um trecho do material. Cada um deles deveria ser apresentado de uma maneira diferente: em forma de jogral, música, teatro, receita, cruzadinha, poesia, acróstico. 
Nessa cena, o enquadramento foi forte $(\mathrm{E}++)$, no ritmo dos conteúdos a serem abordados, conforme análise tecida a partir da utilização do instrumento contido no quadro A, exposto no anexo deste artigo. Os conteúdos programados para a aula constaram como totalmente fornecidos e contemplados, independentemente do desempenho apresentado pelos grupos. O texto na aula em questão deveria ser estudado pelos alunos porque na semana posterior deveriam apresentar o que pudessem entender de suas leituras.

Verificou-se que, nos critérios relativos à avaliação, a situação se inverteu (E--) com o mais baixo enquadramento. Em relação ao indicador na apreciação dos trabalhos dos alunos, conforme verifica-se com a análise efetuada a partir do quadro $\mathrm{C}$, não foi observada a intervenção da professora na apresentação elaborada pelo grupo observado, pouco importando o tipo de compreensão e apresentação elaborada.

Nos critérios de avaliação, quanto ao indicador questionamento discente, o enquadramento também foi fraco, conforme verificado a partir do instrumento contido no quadro D. Uma aluna perguntou o motivo de precisar realizar o mesmo tipo de atividade da semana anterior e não obteve a resposta disso. Especialmente pelo fato de a disciplina tratar dos modos de agir para ensinar, seria fundamental a ocorrência da discussão a respeito das experiências propostas pela professora a serem vivenciadas nas aulas.

No que tange ao indicador nos questionamentos e desafios aos alunos, conforme análise propiciada pelo instrumento contido no quadro $\mathrm{E}$, exposto no anexo deste artigo, a professora solicitou o estudo do texto para apresentação na semana seguinte, mas não o explicou antes disso. Sequer explicou o motivo de sua seleção, aceitando todas as elaborações dos alunos enquanto satisfatórias para apresentação.

\section{Cena B}

Às 19h30, a professora chegou à sala de aula e avisou novamente que as apresentações deveriam ocorrer naquele dia. Os grupos aos poucos foram chegando e tentando se organizar. Somente às $20 \mathrm{~h} 10$, um grupo se prontificou a levantar para apresentação.

Exemplos de apresentação:

a) Grupo do jogral

Marquem as palavras - é a primeira página

Competência e qualidade na docência - tiramos as palavras-chave e preparamos um jogral.

Competência é o que se pratica.

É o ensino de boa qualidade.

Capacidade é o que se armazena.

Se viermos à faculdade e não aplicarmos o que vemos aqui, ficaremos só com a capacidade, que é o que se armazena.

Palmas do grupo e da professora. b) Grupo do teatro

Duas professoras (alunas) conversaram.

- Nosso ensino é de qualidade.

- Todos os nossos professores são qualificados.

- Espero que você seja uma professora de qualidade.

- O que é qualidade?

- Vou fazer uma pesquisa no Google.

- Nossa, mas o dicionário não fala bem o quero saber.

- Vou ver Aristóteles.

Leitura da definição de qualidade.

Agora sim vou conseguir ser uma professora de qualidade, seguindo essa pesquisa que fiz.

Palmas do grupo e da professora.

Em nenhum momento ocorreram intervenções nas apresentações. Ao final, a professora manifestou-se da seguinte forma:

- Vocês foram muito dedicados, teve grupo que se sobressaiu mais por conta do sorteio. Vocês leram e extraíram bem a ideia.

$\mathrm{Na}$ sequência, avisou que trabalhariam com A Pedagogia da autonomia (FREIRE, 1996), porque quem não leu não poderia sair do curso sem ler, pois o autor é matéria de concurso.

Às 20h50, os alunos foram para o intervalo.

Excerto - Os alunos apresentaram os trechos do texto pelos quais ficaram responsáveis. Cada grupo falou sobre as competências e sobre a qualidade na docência, fazendo um tipo de apresentação: cantando uma música, expondo um jogral, passando uma cruzadinha na lousa, apresentando um diálogo entre os componentes do grupo, entre outras propostas.

Nessa cena, o enquadramento também foi forte $(\mathrm{E}++)$, no ritmo dos conteúdos a serem abordados, pois a professora solicitou que os alunos fizessem as apresentações, sem perguntar se o tempo dado para o seu preparo foi suficiente ao entendimento dos conteúdos e preparo das apresentações. E, mesmo com a precariedade das manifestações discentes, a professora não disponibilizou o tempo da aula seguinte à discussão dos conteúdos a fim de atender às necessidades de trabalho com os assuntos em pauta na disciplina.

Nos critérios relativos à avaliação, quanto ao indicador nos questionamentos ou desafios aos alunos, a situação foi a oposta, com o mais fraco enquadramento (E--). Ficou ressaltado que, mesmo sem explicar as competências para ensinar, sem expor as contribuições do texto selecionado, a professora determinou que os alunos apresentassem os trabalhos sobre as noções apontadas por Rios (2002). Depois disso, mesmo sem explicar o texto, com os grupos demorando bastante para se organizar à frente da sala para as apresentações, a professora ficou no aguardo, pois eles deveriam apresentar os conteúdos expostos nos trechos lidos do texto sobre as competências e a sobre a qualidade na docência. Após as exposições, mesmo com 
a precariedade delas, a professora não interferiu a fim de auxiliar nas discussões. Apenas fez elogios, não realizou correções ou estimulou os alunos à discussão para suscitálos à reflexão.

\section{Cena C}

Às 19h30, a professora chegou à aula e avisou que os alunos trabalhariam com o texto sobre a formação do professor reflexivo, de Isabel Alarcão (2002), fazendo leitura em grupo e destacando ideias principais. O texto foi dividido em tópicos para os grupos. Às $21 \mathrm{~h}$, a professora comunicou que voltaria às $21 \mathrm{~h} 30$ para ouvir o que os grupos levantaram da leitura.

Excerto - A aula foi reservada à leitura de trechos do texto de Isabel Alarcão. E a professora avisou que os alunos deveriam ler o texto, dividindo-o em tópicos para destiná-los à leitura dos grupos.

Em relação ao ritmo nessa etapa da aula, os conteúdos programados constaram como contemplados; em nenhum momento foi proposto que os alunos fizessem a leitura em casa para que a aula fosse usada para aprofundar o trabalho com os conteúdos abarcados anteriormente, pois o tema da aula em pauta era o professor reflexivo. Por tais características, o ritmo foi definido como muito forte $(\mathrm{E}++)$.

De outro lado, nos critérios de avaliação, no indicador dos conteúdos a abordar, as explicações ou discussões foram pouco pormenorizadas, podendo ser vagas do ponto de vista pedagógico, recebendo caracterização fraca (E-). Para explicara realização da leitura, não foram estabelecidas relações entre a noção de reflexão abarcada e as possibilidades de reflexão de práticas pedagógicas veiculadas na educação infantil e nos anos iniciais do Ensino Fundamental, nas diferentes faixas etárias, contemplando as especificidades das exigências de atuação do pedagogo para as diferentes fases do desenvolvimento. Não foram contempladas as origens dos estudos sobre a ideia de reflexão, naturalizando o slogan do termo em pauta. Os alunos não foram suscitados a pensar na noção, tendo como subsídios os exemplos de práticas de ensino das áreas de atuação do professor polivalente. Não houve sequer questionamento sobre a compreensão.

\section{Cena D}

21h30: A maioria dos grupos não tinha feito a leitura solicitada na aula, antes do intervalo, de parte do texto da Isabel Alarcão, e continuou sem ler. Às $21 \mathrm{~h} 40$, a professora voltou para a sala de aula e formou um círculo com os alunos. Comentou sobre a prova da instituição que os alunos fariam e depois passou a conversar com eles sobre o texto:
Profa.: Professor reflexivo tem que ser criativo, atuar de forma inteligente, tem que saber criar e não pode copiar a ideia dos outros, tem que ser flexível. E a relação com o filme? (Escritores da liberdade - 2007 - , assistido em aula anterior).

Alunos: Eu não vi; eu também não...

Aluna: Houve uma crise de comportamento nos profissionais. A gente vê a discussão entre tradicional e construtivismo. No tradicional, você sempre fica do mesmo jeito, cópia, decoreba.

Profa.: Cuidado com a confusão entre construir conhecimento e a falta de intervenção, o tradicional tem muito de positivo. É dificil. Talvez por não ser entendido, o aluno chega à $5^{a}$ série sem saber ler e escrever, pela falta de intervenção. Vocês assistiram à palestra na quinta?

Alunos: Não.

Profa.: A primeira falou sobre a leitura e sobre a escrita. A segunda deu um show; ela explicon e deu dicas sobre as hipóteses e sobre a fase das crianças. Só você foi?

Aluna: Só.

Profa: Que bom seria uma aula daquela professora para os pais; eles não ficariam tão ansiosos no início do processo de alfabetização. Ela tem profundo conhecimento. Ela filmou as aulas dela, e pode auxiliar no processo de construção. Cuidado ao criticar e avaliar sem refletir sobre o que é importante. Quem viu o filme? (O filme foi passado na aula). Até perdi a voz. Quantos viram? (Menos de dez levantaram a mão). Como o professor pode fazer reflexão de um modo prático? Ele reflete a partir de quê?

Aluna: Das situações de sala de aula.

Profa.: Por isso tem que observar. O texto é tão grande e ninguém fala. O que mais? Pedi duas ideias para cada grupo porque o texto é longo.

Aluna: Nós destacamos a formação coletiva - deixar a formação individual e focar a coletiva.

Profa.: Como pode acontecer na escola?

Aluna: A vivência na sala de aula.

Profa.: Mas, em que momentos? Reunião, htpc, formação continuada, é previsto em lei, mas muitas vezes não aproveitamos as reuniões para refletir sobre a prática pedagógica "lá vem aquele textinho de novo". A formação continuada, antes de mais nada, tem que partir de nós mesmos. A professora que trouxe a palestra tem profundo conhecimento porque tem a teoria e a prática. Não tem como separar a teoria da prática. Hoje quem fez o magistério observa que tem muito mais técnica. Quando tínhamos o magistério, o foco era a técnica, e o pedagogo era o teórico. Hoje está tudo no curso de Pedagogia. Se hoje eu não tenho magistério, como resolver essa situação? Aluna: Estágio.

Profa.: Só o estágio não dá conta. Ajuda, mas nem sempre contamos com profissionais com os quais temos a aprender; tem que estudar..

Aluna: A professora (do filme) tinha um sonho, a fragilidade dele é tão grande, levanta aquele trabalho bonito, mas esquece a vida dela.

Profa.: Mas ela é reflexiva.

Aluna: Sim, extremamente. Ela observou os alunos dela; ela refletiu para pensar numa prática. Ela percebeu a diferença entre os grupos; os professores não refletiam, nem a diretora. 
Profa. Que exemplo vem de um aluno reflexivo?

Aluna: A que mudou de turma.

Profa. A professora fez o sistema educacional local refletir.

Aluna: É preciso vencer a inércia. O professor precisa querer buscar, querer salvar as pessoas. É cômodo ficar quieto, desistir.

Profa. Temos às vezes a impressão de que quem dá aula para os menores é menor. Por que professor de $5^{\circ}$ ano ganha mais que o de maternal? Tem aluno que fala que quer crescer aqui na Pedagogia. Será que não podemos fazer um trabalho na turma de maternal sendo professor iniciante ou experiente? Por outro lado, tem professor muito acomodado.

Aluna: Onde eu trabalhava era todo mundo acomodado.

Profa: É nítido quando o trabalho do professor é sério. Os pais percebem.

Aluna: No berçário também, eu fui ver nas escolas. Numa há muitas atividades e noutras, nada.

Profa: Claro. No berçário tem todos os espaços, tem o trabalho com a musicalização.

Aluna: Fico comparando o meu filho comigo. Meu filho no maternal já aprendeu a reconhecer todas as letras, cores. Eu só fui aprender no pré.

Profa: A criança fala lilás, eu só fui aprender isso tarde.

Viram a reportagem da Veja: A escola tem a cara do diretor...Em nome da maldita estabilidade, a educação está como está; tem professor de escola pública que reclama que tem que estudar na escola onde está, dizendo que se sente numa escola particular. Sem controle, o ser humano anda? Lembrando que o coordenador pedagógico não tem função de fiscalizar, mas de orientar, apontar caminhos.

Aluna: No filme, quando pega os cadernos e lê tudo que escreveram, ela quis ler e ninguém quis saber.

Profa: A reflexão passa pela ação, precisa pesquisar, estudar, agir.

Aluna: Eu achei que ela ia desistir. Eu falei: ela vai embora. Depois vi que criou várias situações show de bola.

Profa: A percepção dela quando viu que eles não sabiam sobre o holocausto foi muito boa. A escola muitas vezes é lugar de reprodução, mas ela criou ambiente de aprendizagem - eu só posso quebrar as barreiras quando saio do palanque.

Aluna: Gostei porque ela mudou o vocabulário para falar com os alunos.

Profa: Ela pesquisava, ela trabalhava muito mais que um outro professor qualquer, só acho que não devia ter perdido o marido.

Aluna: Ela conseguiu virar o jogo.

Profa: Ela fala das estratégias - e a professora usa isso para narrar para o supervisor de ensino. A Alarcão vai falar das narrativas, dos portugueses. O que é reflexão? Como vou refletir? Ela pontua várias estratégias que podem ser usadas para essa reflexão. Quem não assistiu, precisa assistir para pensar como ela refletiu. O professor precisa refletir. Mas o que é essa reflexão?

Com a pergunta acima, o trabalho com o texto foi encerrado.
Excerto - A professora pretendeu explicar o que é a noção de professor reflexivo a partir das ideias de Isabel Alarcão e do filme que foi passado na aula anterior da disciplina, Escritores da liberdade. Enfatizou a formação continuada como fundamental para o exercício docente e estabeleceu um diálogo com os alunos sobre as relações entre o filme e a noção de professor reflexivo, a fim de evidenciar como a professora do filme foi reflexiva.

Em relação ao ritmo, mesmo com a baixa participação dos alunos, com o fato de muitos não terem lido o texto e nem assistido ao filme, ela continuou tratando do tema da reflexão como se eles tivessem feito as atividades solicitadas. Contentou-se com os poucos comentários realizados e considerando os assuntos como trabalhados ao término do tempo destinado à aula naquela noite. Essa situação foi definida com muito forte enquadramento $(\mathrm{E}++)$. Aquele era o tempo para o tema e para encerrá-lo.

Quanto aos critérios de avaliação, no indicador nos conteúdos a abordar, as explicações ou discussões foram pouco pormenorizadas e exemplificadas, podendo ser vagas do ponto de vista pedagógico (E-). A professora afirmou que o professor reflexivo não copia a ideia dos outros, como se o docente iniciante não necessitasse de modelos diversos à adaptação nos seus âmbitos de atuação. As discussões sobre a reflexão foram extremamente vagas, e em nenhum momento o termo foi explicado em relação à origem de seu uso ou ao que de fato representa e a como passou a ser veiculado. Os detalhes do filme não foram explicados para que as facetas das práticas pedagógicas nele verificadas fossem contextualizadas na relação com o cenário sociocultural lá apresentado e nas demais relações que poderiam ser pensadas no contexto brasileiro. O termo professor reflexivo foi tratado em aula enquanto sinônimo da noção de professor capaz de obter sucesso em seu trabalho.

Vale ressaltar que a maioria dos grupos não se manifestou em relação às ideias que deveriam ser apresentadas de suas leituras. E isso não foi efetivamente questionado pela professora, que sequer solicitou por escrito o trabalho para a semana seguinte na tentativa de propiciar o contato dos alunos com o material escrito.

Em relação aos poucos alunos que se manifestaram, qualquer ideia mencionada foi aceita, recebendo, por isso, a qualificação menos forte (E--).

Nesse contexto de análises das cenas, vale mencionar resultados de pesquisas que auxiliam no entendimento do cenário aqui exposto e analisado. Assim, é importante considerar que o grupo intitulado Estudos Sociológicos da Sala de Aula - ESSA (NEVES; MORAIS, 2009) desempenhou esforços a fim de aperfeiçoar práticas visando ao sucesso escolar discente; a aprendizagem foi estudada pelos pesquisadores que compõem esse grupo ao 
longo de todo o sistema educativo, pautando-se na teoria de Bernstein. Apesar de esses estudos serem centrados na educação científica, geraram resultados significativos para se discutir outras áreas, como a aqui estudada. Foram construídos modelos para dirigir a investigação e para analisar os resultados obtidos. O grupo chegou a um modelo de prática que lhe pareceu ter o potencial para levar os alunos ao sucesso, com o objetivo de diminuir a diferença entre alunos de origens sociais diferentes. As características sociológicas da modalidade de prática que se mostraram fundamentais para a aprendizagem dos alunos, especificamente quanto aos aspectos aqui focalizados, foram: a) tempo de aquisição controlado pelos alunos - enquadramento fraco no nível do ritmo; b) explicitação clara do texto legítimo a ser adquirido no contexto da sala de aula - enquadramento forte no nível dos critérios de avaliação (MORAIS; NEVES, 2009). Verifica-se, no cotejo com a situação proposta por elas, que a pesquisa aqui relatada é quase exatamente o contrário, pois as características da sala de aula pesquisada demonstraram valores opostos.

Nessa dinâmica, as práticas pedagógicas estabelecidas no ensino da Didática revelam que o enquadramento forte no que se refere ao ritmo gera entraves à aprendizagem. É muito importante que o aluno possa controlar e estabelecer as suas necessidades de tempo ao entendimento dos conteúdos e elaboração das atividades a eles relacionadas. É fundamental o poder de decisão por parte do futuro professor em relação às suas demandas de tempo para estabelecer as relações necessárias no trabalho com os conteúdos da área. Entretanto, as práticas revelaram o controle do ritmo centralizado no professor, desconsiderando as necessidades discentes em relação especialmente à aprendizagem e também ao tempo de trabalho com os conteúdos.

Considera-se que, principalmente por se tratar de um curso superior, seria fundamental que os alunos investissem na sua própria formação, dedicando-se às leituras. Seria essencial que a professora aproveitasse os momentos de discussão para esclarecer aos alunos os conteúdos abordados no texto. O entrave maior detectado nas análises pode ser representado pelo fato de a professora não ter levado em consideração as necessidades discentes durante as discussões dos textos. Assim, os alunos não se apropriaram nem das ideias principais dos materiais trabalhados. E a professora não fez intervenção a esse respeito, seguindo a sequência de sua programação no tempo previsto a ela destinado, mesmo sem os alunos concederem algum indício de que aprenderam.

Os critérios de avaliação revelando o fraco enquadramento também merecem destaque, pois é fundamental que as práticas em relação aos indicadores que dizem respeito a estes sejam bastante pormenorizadas.
Ou seja, as explicações dos conteúdos, as respostas aos questionamentos, os desafios propostos aos discentes e as apreciações às suas apresentações precisam ser bem detalhados e exemplificados para aumentar as possibilidades de conhecimento e desenvolvimento de habilidades do discente, e, então, revelar forte grau de enquadramento (AFONSO, MORAIS, NEVES, 2002). Assim, o débil enquadramento verificado nas práticas observadas no campo empírico constitui-se como um limitador da formação da consciência profissional necessária ao futuro professor. Nesse caso, é importante considerar que:

um enfraquecimento do enquadramento a nível dos critérios de avaliação [...] deixa os alunos que entraram em desvantagem na escola cada vez mais desfavorecidos - há um texto legitimado e valorizado pela escola e pela sociedade para ser aprendido e todos os alunos devem ter acesso a esse texto (MORAIS, 2001, p. 16).

Essas questões são muito pertinentes para as discussões aqui estabelecidas, pois muitas vezes o alunado do curso em questão, que vivenciou práticas com os débeis critérios de avaliação, como as aqui analisadas, já é egresso da escola de educação básica de qualidade discutível. Portanto, provavelmente, não teve acesso a esse texto legitimado e valorizado, que é a cobrança rigorosa, e, ao cursar um ensino superior que novamente lhe nega o acesso a adquiri-lo, mais uma vez tem os seus direitos negados. O que tende a se propagar, ainda, na sua prática profissional, com a limitação de sua consciência para o exercício docente, gerando um perverso processo de exclusão ao acesso ao conhecimento que estava sob foco.

As práticas de desrespeito em relação ao ritmo do aluno, a não explicitação pormenorizada de conteúdos, a frequente ausência de discussão e trabalho efetivo com as conquistas do aluno, agravada pela falta de correções ao aprimoramento discente, tendem a erradicar qualquer possibilidade de sucesso no trabalho com os discursos valorizados pela área no que tange aos modos de agir para ensinar. Considerando, assim, a dimensão sociopolítica dos processos de escolarização e do trabalho docente e limitando a formação da consciência profissional necessária ao exercício do magistério.

Ressalta-se que as evidências que se referem ao controle de ritmo e aos critérios de avaliação nas práticas de sala de aula precisam ser cuidadosamente observadas e conduzidas pelos formadores no trabalho de formar professores, especialmente se levada em consideração a dimensão alegada, muitas vezes, de que os professores ensinam aos seus alunos como foram ensinados por seus professores. Com a manutenção de características, 
como as das análises da observação desses indicadores das práticas no trabalho com a Didática, verifica-se, aqui, a tendência da interdição de qualquer possibilidade bem-sucedida. No sentido de romper com a perspectiva de que os aspectos negativos verificados sejam superados. Igualmente, não se verificou a presença de outros tipos de atividades para além das propostas aqui relatadas, seja para complementar ou enriquecer ampliando a compreensão quer dos conceitos, quer da realidade. De modo que tais práticas jamais se assemelhassem à fragmentação dos textos promovida nas dinâmicas observadas, em que cada grupo fazia a leitura apenas de trechos dos materiais. E era isso que ocorria mediante o barulho da chegada da turma.

Nesse contexto analítico, acrescenta-se que ainda é preciso considerar que há características das práticas pedagógicas interligadas. Tais características remetem a aspectos que deveriam ser valorizados de visar à discussão e, para isso, seria adequada a criação de situações semanais que promovessem a leitura das obras por parte do alunado e sua exposição. Contando, assim, com registros escritos e debates e a partir disso estabelecendo relações. Além de tais características, que não aconteceram, essa interligação deve ocorrer entre os critérios de avaliação explícitos $(\mathrm{E}++)$ e exige que os alunos tenham controle no ritmo (E--), de forma que haja tempo, no discurso, para explicitar os critérios. Demanda ainda que os adquirentes tenham controle no nível das regras hierárquicas (E--), de modo que possam levantar questões livremente e discutir seus questionamentos, conforme apontam Neves e Morais (2009). Aspectos extremamente distantes das práticas observadas, nas quais predominam a ausência de discussões e a escassez de questionamentos, ou seja, exatamente o contrário.

\section{MAIS ALGUMAS CONSIDERAÇõES}

Lamentavelmente, o como do trabalho evidenciado por meio das relações analisadas constitui, também, conteúdo da disciplina, pela especificidade da área sob enfoque. E potencializa o estabelecimento desses tipos de práticas de exercício de controle na futura atuação profissional, pois muitas vezes os docentes ensinam aos seus alunos da forma como foram ensinados pelos seus professores.

Os indicadores analisados revelaram, em sua maioria, que as contribuições do ensino da Didática almejadas para uma boa formação do professor não foram potencializadas pelas relações estabelecidas. As características das práticas ressalvam que os alunos não são socializados intencionalmente para questionar e não participam de debates de elaboração conjunta entre eles e o professor. Os alunos são submetidos a aulas de Didática destinadas apenas ao cumprimento de tarefas que sequer são discutidas pelos grupos no sentido de possibilitar a formação do conhecimento didático que se requer ao professor. Dessa forma, são impelidos a um provável papel de submissão pelo despreparo sociopolítico e técnico no âmbito das suas possíveis atuações no exercício do magistério, tendendo a contribuir à precarização dos processos de formação propiciados à maioria da infância brasileira.

A partir da observação das aulas, o conceito de enquadramento possibilitou a análise rigorosa de aspectos relacionados ao modo pelo qual a comunicação ocorre no trabalho com os conteúdos da Didática, perfazendo o código. Isso porque tais conceitos trazem contribuições ao entendimento dos mecanismos entranhados nas práticas pedagógicas em contextos instrucionais, gerando indícios diversos sobre a lógica da formação das consciências dos futuros professores. Induzindo-os a um exercício profissional que tende a reproduzir as injustiças sociais por seu despreparo técnico e político para esse tipo de atuação. Portanto, tais análises geram pistas à necessidade de modificação dessa lógica vigente, de formação e, consequentemente, da escolarização da infância, que prevalece nas práticas na relação entre professor e alunos. Alternativas podem ser subsidiadas pelo estabelecimento de relações mais promissoras para os processos de formação de professores.

Por fim, ressalta-se que, se quaisquer valores de classificação e enquadramento em conjunto geram a modalidade do código, ou seja, a formação, a mensagem formativa subjacente ao que ocorre nas comunicações de todas as ações, pode-se também afirmar que os mecanismos instaurados nas aulas de Didática do curso de Pedagogia observado contribuem para uma socialização profissional futura desses graduandos. Destinada esta, de um lado à subordinação aos seus superiores, ao aligeiramento do conhecimento; e, de outro, ao mandonismo em relação a seus alunos. Tende a conduzir esses alunos a nada reivindicar no exercício da profissão, a apenas cumprir as tarefas que lhes serão concedidas. O que se constata frequentemente nas cenas em que a ausência de discussão sobre o para que, o que e o como dos modos de agir para ensinar no exercício do professor polivalente perfaz o conjunto formativo propiciado na disciplina.

\section{Referências}

AFONSO, Margarida; MORAIS, Ana Maria; NEVES, Isabel. Contextos de formação de professores: Estudo de características sociológicas específicas. Revista de Educação, Lisboa, v. XI, n. 1, p. 129-146, jan.-jul. 2002.

ALARCÃO, Isabel. A formação do professor reflexivo. In: ALARCÃO, Isabel. Professores reflexivos numa escola reflexiva. São Paulo: Cortez, 2002. p. 43-93. 
BARBIER, Jean Marie. A avaliação em formação. Porto: Edições Afrontamento, 1990.

BERNSTEIN, Basil. A estruturação do discurso pedagógico: classe, códigos e controle. Tradução de Tomaz T. da Silva e Luís F. G. Pereira. Petrópolis: Vozes, 1996. Coleção Ciências Sociais da Educação.

BERNSTEIN, Basil. Pedagogía, control simbólico e identidad: teoría, investigación y crítica. Madrid: Morata; La Coruña: Fundación Paideia, 1998. Colección Educación Crítica.

ESCRITORES da liberdade (FreedomWriters, 2007). Direção e Roteiro de Richard LaGravenese, baseado no livro de Erin Gruwell. Distribuidora Paramount Pictures. Alemanha/Estados Unidos: 2007. DVD. Colorido. Legendado. $123 \mathrm{~min}$.

FREIRE, Paulo. Pedagogia da autonomia. São Paulo: Paz e Terra, 1996.

GALIAN, Cláudia Valentina Assumpção. A recontextualização do conhecimento científico: os desafios da constituição do conhecimento escolar. Tese (Doutorado em Educação: História, Política, Sociedade) - Pontifícia Universidade Católica de São Paulo, 2009.

GIOVANNI, Luciana Maria; MARIN, Alda Junqueira (Orgs.). Professores iniciantes: diferentes necessidades em diferentes contextos. Araraquara: Junqueira \& Marin, 2014.

GOMES, Suzana dos Santos. Um olhar sobre as práticas de avaliação na escola. Belo Horizonte: Mazza, 2014.
LUCKESI, Cipriano Carlos. Avaliação da aprendizagem escolar. São Paulo: Cortez, 1995.

MARIN, Alda Junqueira. Didática e Currículo: conceitos, pesquisa e necessidade de avanço. In: IV Colóquio lusobrasileiro sobre questões curriculares/VII Colóquio sobre Questões Curriculares. Anais. Florianópolis, 2008.

MARIN, Alda Junqueira; PENNA, Marieta Gouveia Oliveira; RODRIGUES, Ana Carolina Colacioppo. A Didática e a formação de professores. Revista Diálogo Educacional, Curitiba, v. 12, n. 35, p. 51-77, jan./abr. 2012.

MORAIS, Ana Maria. Práticas pedagógicas na formação inicial e práticas dos professores. Seminário Modelos e Práticas de Formação Inicial de Professores. Universidade de Lisboa, 2001. Disponível em: <http://www.educ.fc.ul.pt/recentes/ mpfip/pdfs/ammorais. pdf>. Acesso em: 09 set. 2009.

MORAIS, Ana Maria; NEVES, Isabel Pestana. A teoria de Basil Bernstein: alguns aspectos fundamentais. Práxis Educativa, Ponta Grossa, v. 2, n. 2, p. 115-130, jul./dez. 2007.

MORAIS, Ana Maria; NEVES, Isabel Pestana. Textos e contextos educativos que promovem aprendizagem. Optimização de um modelo de prática pedagógica. Revista Portuguesa de Educação, Braga, v. 1, n. 22, p. 5-28, jan./jul. 2009.

RIOS, Terezinha Azeredo. Competência e qualidade na docência. In: RIOS, Terezinha Azeredo. Compreender e ensinar: por uma docência de melhor qualidade. São Paulo: Cortez, 2002. p. 63-92.

\section{ANEXo \\ Lista de quadros - instrumentos de análise das práticas pedagógicas ${ }^{2}$}

Quadro A. Ritmo - Nos conteúdos a abordar

\begin{tabular}{|l|l|l|l|l|}
\hline \multicolumn{1}{|c|}{ Indicador } & \multicolumn{1}{|c|}{ E++ } & \multicolumn{1}{|c|}{ E+ } & \multicolumn{1}{|c|}{ E- } \\
\hline $\begin{array}{l}\text { Nos conteúdos a } \\
\text { abordar }\end{array}$ & $\begin{array}{l}\text { Os conteúdos } \\
\text { programados para } \\
\text { a aula têm de ser } \\
\text { rigorosamente } \\
\text { abarcados. }\end{array}$ & $\begin{array}{l}\text { Alguns conteúdos } \\
\text { podem ser pontualmente } \\
\text { adiados. }\end{array}$ & $\begin{array}{l}\text { A programação dos } \\
\text { conteúdos é flexível } \\
\text { para admitir adiamentos } \\
\text { se determinadas } \\
\text { situações o justificarem. }\end{array}$ & $\begin{array}{l}\text { Os alunos determinam } \\
\text { o tempo necessário } \\
\text { assuntoração de cada } \\
\text { não contemplados ficam } \\
\text { adiados. }\end{array}$ \\
\hline
\end{tabular}

Quadro B. Critérios de avaliação - Nos conteúdos a abordar

\begin{tabular}{|l|l|l|l|l|}
\hline \multicolumn{1}{|c|}{ Indicador } & \multicolumn{1}{|c|}{ E++ } & \multicolumn{1}{|c|}{ E+ } & \multicolumn{1}{|c|}{ E- } & \multicolumn{1}{|c|}{ E-- } \\
\hline $\begin{array}{l}\text { Nos conteúdos em } \\
\text { estudo }\end{array}$ & $\begin{array}{l}\text { As explicações } \\
\text { ou discussões são } \\
\text { pormenorizadas } \\
\text { e exemplificadas } \\
\text { claramente, sendo } \\
\text { corretas do ponto de } \\
\text { vista pedagógico. }\end{array}$ & $\begin{array}{l}\text { As explicações } \\
\text { ou discussões dos } \\
\text { conhecimentos são } \\
\text { pormenorizadas e } \\
\text { exemplificadas, sendo } \\
\text { genericamente corretas. }\end{array}$ & $\begin{array}{l}\text { As explicações ou } \\
\text { discussões são pouco } \\
\text { pormenorizadas } \\
\text { e exemplificadas, } \\
\text { podendo ser vagas } \\
\text { do ponto de vista } \\
\text { pedagógico. }\end{array}$ & $\begin{array}{l}\text { As explicações ou } \\
\text { discussões não são } \\
\text { pormenorizadas, } \\
\text { nem exemplificadas } \\
\text { claramente, podendo ser } \\
\text { confusas ou incorretas } \\
\text { do ponto de vista } \\
\text { pedagógico. }\end{array}$ \\
\hline
\end{tabular}

\footnotetext{
${ }^{2}$ Quadros elaborados a partir da análise da produção do grupo de pesquisa ESSA.
} 
Quadro C. Critérios de avaliação - Na apreciação dos trabalhos dos alunos

\begin{tabular}{|l|l|l|l|l|}
\hline \multicolumn{1}{|c|}{ Indicador } & \multicolumn{1}{|c|}{ E++ } & \multicolumn{1}{|c|}{ E+ } & \multicolumn{1}{|c|}{ E- } & \multicolumn{1}{|c|}{ E-- } \\
\hline $\begin{array}{l}\text { Apreciação dos } \\
\text { trabalhos dos alunos }\end{array}$ & $\begin{array}{l}\text { A professora indica aos } \\
\text { alunos, com bastante } \\
\text { clareza e detalhamento, } \\
\text { o que está errado, o que } \\
\text { falta nos trabalhos e } \\
\text { formas de melhorá-los, } \\
\text { em consonância com } \\
\text { aquilo que se pretende. }\end{array}$ & $\begin{array}{l}\text { A professora indica } \\
\text { aos alunos o que está } \\
\text { errado, o que falta nos } \\
\text { trabalhos e formas } \\
\text { de melhorá-los, em } \\
\text { consonância com aquilo } \\
\text { que se pretende. }\end{array}$ & $\begin{array}{l}\text { A professora coloca } \\
\text { algumas questões aos } \\
\text { alunos acerca dos } \\
\text { seus trabalhos, mas } \\
\text { não deixa claro o que } \\
\text { está errado ou falta, } \\
\text { nem indica formas de } \\
\text { melhorá-los. }\end{array}$ & $\begin{array}{l}\text { A professora não coloca } \\
\text { quaisquer questões } \\
\text { aos alunos acerca dos } \\
\text { trabalhos. }\end{array}$ \\
\\
\cline { 1 - 3 }
\end{tabular}

Quadro D. Critérios de avaliação - No questionamento discente

\begin{tabular}{|l|l|l|l|l|}
\hline \multicolumn{1}{|c|}{ Indicador } & \multicolumn{1}{|c|}{ E++ } & \multicolumn{1}{|c|}{ E+ } & \multicolumn{1}{|c|}{ E- } & \multicolumn{1}{|c|}{ E-- } \\
\hline $\begin{array}{l}\text { Questionamento } \\
\text { discente }\end{array}$ & $\begin{array}{l}\text { A professora, através de } \\
\text { diálogo com os alunos, } \\
\text { esclarece as dúvidas de } \\
\text { forma pormenorizada, } \\
\text { levando-os à resposta } \\
\text { correta. }\end{array}$ & $\begin{array}{l}\text { A professora esclarece } \\
\text { as dúvidas dos alunos, } \\
\text { fornecendo-lhes a } \\
\text { resposta correta de } \\
\text { forma pormenorizada. }\end{array}$ & $\begin{array}{l}\text { A professora esclarece } \\
\text { as dúvidas dos alunos, } \\
\text { dando uma resposta de } \\
\text { caráter genérico. }\end{array}$ & $\begin{array}{l}\text { A professora não } \\
\text { esclarece as dúvidas dos } \\
\text { alunos. }\end{array}$ \\
\end{tabular}

Quadro E. Critérios de avaliação - Nos questionamentos/desafios aos alunos

\begin{tabular}{|l|l|l|l|l|}
\hline \multicolumn{1}{|c|}{ Indicador } & \multicolumn{1}{|c|}{ E++ } & \multicolumn{1}{c|}{ E+ } & \multicolumn{1}{|c|}{ E- } & \multicolumn{1}{|c|}{ E-- } \\
\hline $\begin{array}{l}\text { Nos questionamentos/ } \\
\text { desafios aos alunos }\end{array}$ & $\begin{array}{l}\text { A professora questiona/ } \\
\text { desafia os alunos de } \\
\text { forma pormenorizada, } \\
\text { levando-os às respostas } \\
\text { corretas. }\end{array}$ & $\begin{array}{l}\text { A professora questiona/ } \\
\text { provoca os alunos } \\
\text { de forma menos } \\
\text { pormenorizada, dando } \\
\text { alternativas a respostas. }\end{array}$ & $\begin{array}{l}\text { A professora questiona } \\
\text { os alunos de forma } \\
\text { pouco detalhada, } \\
\text { aceitando uma resposta } \\
\text { de caráter genérico. }\end{array}$ & $\begin{array}{l}\text { A professora questiona } \\
\text { os alunos, aceitando } \\
\text { como correta qualquer } \\
\text { resposta. }\end{array}$ \\
\hline
\end{tabular}

